\title{
区域镇村社区空间网络结构特征及其优化策略
}

\author{
宿 瑞 1,2 , 王 成 ${ }^{1,2^{*}}$, 唐 宁 ${ }^{1,2}$, 彭 清 1,2 , 龙玉琴 1,2
}

(1. 西南大学地理科学学院/乡村人居环境研究实验室, 重庆 400715; 2. 岩溶环境重庆市重点实验室, 重庆 400715)

\begin{abstract}
摘 要: 镇村社区空间网络是以镇区为依托、镇村社区为节点、彼此关联为连边构成的空间组织形态, 探索其结构特 征及其优化策略对引导要素合理流动、提升网络运行效率等具有重要意义。本文选取重庆市沙坪坝区凤凰镇 19 个镇村社区作为网络节点, 采用修正后的引力强度模型反映节点之间的联系, 运用 GIS 工具和社会网络分析法、相 关性分析等方法探究镇村社区空间网络结构的总体特征、节点特征及差异特征, 提出镇村社区空间网络的优化策 略。研究表明:镇村社区空间网络总体处于低水平、非均衡的发展阶段,网络兼具整体松散性与局部集聚性,且小 世界特征较为显著, 凝聚子群之间的关联性差异明显; 镇村社区空间网络呈现 “核心-边缘” 的节点结构, 核心节点 的结构洞优势有待加强;社区居民不同的社会属性对网络结构造成了差异性影响;基于此,拟从节点自身功能完 善、节点等级体系构建及节点间经济联系强化等方面,构建“1轴、1 心、18点”+“1网、57线”的空间网络化模式,为 当前及未来的农村社区建设提供示范。
\end{abstract}

关 键 词: 镇村社区; 空间网络结构; 优化策略; 凤凰镇; 重庆

1 引言

集镇社区与农村社区(以下简称 “镇村社区”)作 为农村社会服务管理的基本单元, 既是第二次生产 分工后农户进行生产物品、生活物品、信息产品的 交流场所, 又肩负着亲缘、血缘及业缘的纽带作用 (石忆邵等, 2013)。伴随新型城镇化、工业化、信息 化及农业现代化进程的快速推进, 镇村社区原有的 单一、封闭、松散化的空间组织形式逐渐被多中心、 流动性、扁平化的网络模式所替代(危小建等, 2017), 即以镇域为基底、镇村社区为节点, 社区相 互联系为连边的空间网络逐渐形成、深化。镇村社 区作为镇村体系的关键节点, 对周围乡镇与农村地 区产生辐射带动作用, 镇村社区的网络联系对域内 资源配置方式、要素流动方向及空间整合等影响巨 大(喻新安等, 2013)。因此, 探究镇村社区空间网络 结构特征并对其优化显得尤为必要。当前研究主
要是基于传统的镇村体系与规模属性分析其空间 联系与网络结构(惠怡安等, 2014; 王凤等, 2016), 或 侧重分析农村居民点与其周围居民点及城镇的相 互作用(苑露莎, 2014); 且镇村社区的研究依然着眼 于个案分析, 即针对单一社区的公共空间(邹晴晴 等, 2016)、空间界面(乔家君, 2012)、人居环境(蔡进 等, 2013)等进行分析, 或对社区居住主体的共生认 知(叶琴丽等, 2015)、管护绩效(蒋文虹等, 2014)、生 计资产(蔡进等, 2015)等进行评价, 对镇村社区相互 作用所呈现的空间网络结构的研究关注较少, 难以 真正、全面地了解区域内镇村社区网络的发展阶段 与发育状况, 使得新型城镇化推进和美丽乡村建设 转型升级缺乏有力的网络理论与方法指导。引力 强度模型(刘耀林等, 2016)与社会网络分析法(刘 军, 2004)作为研究区域联系的重要范式, 在区域经 济联系(李亚婷等, 2014)、社会网络结构(侯贺平等, 2013)等方面得到了广泛应用,成为目前两种较为

收稿日期: 2017-07-24; 修订日期 : 2017-12-06。

基金项目: 国家自然科学基金项目(41741022); 教育部人文社会科学研究规划基金项目(15YJAZH068) [Foundation: National Natural Science Foundation of China, No. 41741022; The MOE (Ministry of Education in China) Project of Humanities and Social Sciences, No.15YJZAH068]。

作者简介:宿瑞(1990-), 男,山西太谷人,硕士研究生, 主要从事土地利用与国土规划研究, E-mail: surui1009@163.com。 通讯作者:王成(1975-), 男, 重庆荣昌人, 教授, 博士生导师, 主要从事土地利用与乡村发展研究, E-mail: wchorange@126.com。 
流行且有效的空间网络研究方法。为此, 本文以重 庆市沙坪坝区凤凰镇镇村社区为例, 采取改进的引 力强度模型与社会网络分析相结合的方法, 构建镇 村社区空间网络, 剖析镇村社区空间网络结构的总 体特征、节点特征及差异特征, 提出镇村社区空间 网络的优化策略, 为丘陵山区农村社区建设提供理 论参考。

\section{2 研究区域与数据整理}

\section{1 研究区概况}

凤凰镇 $\left(106^{\circ} 07^{\prime} 25^{\prime \prime} \mathrm{E} \sim 106^{\circ} 20^{\prime} 31^{\prime \prime} \mathrm{E}, 29^{\circ} 42^{\prime} 10^{\prime \prime} \mathrm{N} \sim\right.$ $\left.29^{\circ} 44^{\prime} 34^{\prime \prime} \mathrm{N}\right)$ 地处重庆市沙坪坝区西北部, 面积 31.7 $\mathrm{km}^{2}$ 。属亚热带季风气候, 地貌类型以低山丘陵为 主, 地势西高东低, 梁滩河过境。渝遂高速公路和 绕城高速公路呈 “十字形”贯穿全镇。全镇辖 1 个集 镇社区和凤凰桥、八字桥、胡南坝、杨家庙、五福、威 灵寺、皇角等 7 个行政村, 人口 2.2 万人。现有工业 企业 200 余家, 企业员工 1 万余人, 从事机械加工和 纺织等产业; 境内自然景色秀美、田园风情浓郁, 凤 凰花海、千年古刹威灵寺以及威灵村洋房子等人文 景观广布。全镇已建成 19 个集中居民点, 包括 1 个 集镇社区和 18 个农村社区, 人口约占全镇总人口的 $50 \%$, 社区成为人口集聚区。域内交通通讯设施较 发达, 非农产业布局分散, 社区居民大多就近为业, 工作、生活等交流频繁, 以地缘业缘关系为主的社 会关系网络逐渐建构。凤凰镇作为沙坪坝区新型 城镇化的重点区域, 镇村社区在推进城乡服务均等 化、乡村振兴等方面发挥了积极作用, 促使城乡之 间的物质流、资金流及信息流等双向流动与优化配 置。为此, 本文综合农村社区的建设标准和丘陵山 区农村居民点的分布特征, 将全域 19 个镇村社区作 为研究对象, 探究镇村社区空间网络结构的总体特 征、节点特征及差异特征, 为促进城乡一体化发展 提供借鉴。

\section{2 数据收集及处理}

本文数据包括两部分: 空间数据来源于研究区 2016年土地利用现状图(1:10 000)和2014年高清遥 感影像图 $(0.6 \mathrm{~m})$; 属性数据中社会经济数据来源于 《沙坪坝区统计年鉴》《重庆市社会事业发展“十三 五” 规划》及研究区各行政村 2010-2015 年农村经济 报表, 社区居民数据来源于 2016 年 10 月-2017年 1 月课题组 4 次实地调查。具体过程如下: 一是问卷 设计。首先, 通过文献梳理和走访镇人民政府、镇
国土资源管理所和各村村民委员会, 了解当地自然 环境、社会经济等基本信息,参照城市社区模式与 新型农村社区建设标准, 设计包括聚居环境、区位 条件、基础服务、居民特征 4 个大项 19 个小项的初 级问卷; 其次, 选择各村干部、社区居民(15户)进行 预调研, 修改、完善调查问卷, 确定问卷内容; 二是 进行调查培训。借助遥感影像, 按照社区分布情 况, 将研究区划分为 4 个片块, 各组调查人员事先进 行培训、演练, 统一调查标准与口径; 三是实地调 查。首先通过 GPS 定位获取每个社区图斑的地理 坐标, 运用参与式农村评估法访问社区居民, 获取 社区居民的属性数据。调查共发放问卷 520 份, 有 效问卷 497 份, 有效率 $95.58 \%$ 。运用 SPSS 22.0 软 件对问卷数据进行信度检验, Cronbach's Alpha系数 值为 $0.872, \mathrm{KMO}$ 值为 0.811 , Bartlett 球型检验的显 著性水平 $s i g<0.001$, 说明问卷设计合理、数据具有 较高的效度。

\section{3 研究方法}

\section{1 引力强度模型及改进}

引力强度模型是基于万有引力公式与距离衰 减原理,由区域经济能量、人口规模、交通距离及介 质系数等 4 项网络要素组成的数理模型, 用于测度 区域之间空间相互作用的大小,刻画区域的经济联 系(Thomas, 1982)。为更好地反映社区之间的相互 关系, 本文采取社区综合质量以表示其经济能量, 镇村社区的常住人口反映人口规模, 并依据社区之 间的实际距离、参照道路等级对交通距离进行修 正, 从而对引力强度模型进行改进, 以反映镇村社 区的相互作用强度。

$$
F_{i j}=k_{i j} \frac{\sqrt{H_{i} P_{i}} \times \sqrt{H_{j} P_{j}}}{d_{i j}^{2}}, k_{i j}=\frac{H_{i}}{H_{i}+H_{j}}
$$

式中: $F_{i j}$ 为 $i, j$ 社区间的引力强度; $H_{i} 、 H_{j}$ 和 $P_{i} 、 P_{j}$ 分别 为 $i, j$ 社区的综合质量和人口规模; $k_{i j}$ 为 $i$ 社区在 $i, j$ 社区中的质量占比, 即介质常数。 $d_{i j}$ 为 $i$ 社区与 $j$ 社 区的交通距离, 即 $d_{i j}=$ 道路实际长度 $\times$ 道路等级修正 系数。道路级别越高, 修正系数越小, 参考《公路工 程技术标准 (JTGB01-2014)》并结合当地实际, 细分 为高速公路、省道和农村道路 (该镇无国道和县道 过境）。考虑到高速公路属于封闭道路, 且一般在 农村没有出人口, 因此设置为不可通行; 省道设置 为 0.2 , 乡 (镇) 道为 0.5 , 村组路为 1 。村与村之间、 
村与镇之间一般取 $0.3 \sim 1$ 。

镇村社区综合质量测算。借鉴已有相关研究 (覃永晖, 2014; 杜相佐等, 2015), 遵循科学性、可操 作性和系统性原则, 融贯镇村社区的现状特征、 潜在影响力及其制约因素, 从聚居环境、区位条件、 基础服务及居民特征 4方面测度其质量。采用 0-1 标准化法对相关指标数据进行标准化、消除量 纲, 并将层次分析法与熵值法相结合以确定指标权 重, 得到镇村社区综合质量评价指标体系及其权重 (表1)。

本文先采用层次分析法对指标赋权, 保证重要 性指标所占权重较大, 再运用熵值法对指标权重进 行调节, 既保证重要性指标所占权重, 又减少层次 分析法的主观、片面性。将主客观赋权法相结合对 镇村社区综合质量指标进行综合赋权, 得到更为合 理和精确的指标权重。公式如下:

$$
r_{i}=\theta_{i} w_{i} / \sum_{i=1}^{n} \theta_{i} w_{i}(i=1,2 \Lambda \Lambda, 19)
$$

式中: $r_{i}$ 为第 $i$ 个指标的权重; $\theta_{i}$ 和 $w_{i}$ 分别为利用层次 分析法和熵权法确定的第 $i$ 个评价指标权重。

运用综合评价法计算镇村社区综合质量, 其公 式为:

$$
H=\sum_{i=1}^{n} h_{i} r_{i}
$$

式中: $H$ 为镇村社区的综合质量值; $h_{i}$ 为第 $i$ 个指标 经标准化处理后的值; $r_{i}$ 为第 $i$ 个指标的权重; $n=19$, 为指标数目。

\section{2 社会网络分析法}

社会网络分析是社会学中研究行动者之间相 互关系的重要方法(甄茂成等, 2013)。通过对行动 者及其彼此关系进行数据收集和分析揭示镇村社 区空间网络结构及其属性特征(付琼鸽等, 2015)。 本文通过对引力强度模型进行改进, 构建镇村社区 空间网络, 对网络结构的总体特征及节点特征进行 分析, 包括网络密度、网络中心势、凝聚子群及小世 界特征分析、中心性与结构洞测算等, 并运用 UCINET 软件进行网络特征计算, 从网络结构的总体指 标和节点指标来剖析网络结构。

(1) 网络密度。指网络中节点间的实际关系数 量与理论最大关系数的比值, 密度值越大, 说明网 络中节点联系越紧密, 网络结构越紧凑、网络功能 越完善。

$$
D=\frac{y}{x(x-1)}
$$

\begin{tabular}{|c|c|c|c|}
\hline 目标层 & 指标层 & 指标内容 & 权重值 \\
\hline \multirow{3}{*}{$\begin{array}{l}\text { 聚居 } \\
\text { 环境 }\end{array}$} & 社区规模 & 2016年土地利用现状图(1:10000)的社区图斑面积 $/ \mathrm{hm}^{2}$ & 0.0692 \\
\hline & 公共管理用地比重 & 社区公共服务用地(即公共建筑和公共设施用地)与社区总面积的比重 $/ \%$ & 0.0487 \\
\hline & 社区整洁度 & 从生态环境、人居环境、社区容貌整洁、卫生设施和住户素质 5 个方面评价, 分为 5 级 & 0.0575 \\
\hline \multirow{4}{*}{$\begin{array}{l}\text { 区位 } \\
\text { 条件 }\end{array}$} & 平均耕作半径 & 社区距离耕作地块的平均距离 $/ \mathrm{km}$ & 0.0498 \\
\hline & 距产业园区距离 & 社区距离农业、工业产业园的最近距离/km & 0.0545 \\
\hline & 距城镇距离 & 社区距离城镇中心位置的距离 $/ \mathrm{km}$ & 0.0528 \\
\hline & 距主要公路距离 & 社区距离主要公路的最近距离/km & 0.0545 \\
\hline \multirow{6}{*}{$\begin{array}{l}\text { 发展 } \\
\text { 基础 }\end{array}$} & 服务设施完善度 & 公共设施(学校、卫生院、小卖部、公则、图书室、便民服务中心、饭店等)数量/个 & 0.0477 \\
\hline & 清洁能源使用率 & 反映清洁能源使用情况: 使用沼气/太阳能/天然气/其他=1,使用项数累加 & 0.0396 \\
\hline & 垃圾处理数量 & 社区垃圾处理设施的配置情况/个 & 0.0443 \\
\hline & 休闲娱乐设施 & 社区休闲娱乐设施的配置情况/个 & 0.0377 \\
\hline & 后期管护力度 & 社区对于基础设施和公共管理的资本投人情况/(月/元) & 0.0457 \\
\hline & 信息通讯费用 & 社区居民使用电话、网络的费用/(月/元) & 0.0447 \\
\hline \multirow{6}{*}{$\begin{array}{l}\text { 居民 } \\
\text { 特征 }\end{array}$} & 居民可支配收人 & 社区内家庭年均可自由支配的收人/(年/元) & 0.0620 \\
\hline & 受教育程度 & 社区内所有人口受教育年限平均值/年 & 0.0671 \\
\hline & 邻里关系 & 社区居民之间交往联系的密切程度, 分为好、较好、一般、较差 4级 & 0.0564 \\
\hline & 主要生计来源 & $\begin{array}{l}\text { 生计来源分为农业规模经营、农业多样化经营、兼业化经营、非农经营及其他收人 } 5 \text { 类。 } \\
\text { 统计社区居民 } 5 \text { 项生计来源的占比情况,将比重最大的作为主要生计来源。 }\end{array}$ & 0.0594 \\
\hline & 人住年份 & 反映社区居民的平均居住时间/年 & 0.0562 \\
\hline & 居住满意度 & 反映社区居民的居住满意程度: 满意 $=1$ 、较满意 $=0.75$ 、一般 $=0.5$ 、不满意 $=0.25$ & 0.0524 \\
\hline
\end{tabular}

表 1 镇村社区综合质量指标体系及其权重

Tab.1 Comprehensive quality evaluation index system and weights of village and town communities 
式中: $D$ 为网络密度, $y$ 为实际存在的有效联系总 数, $x$ 为网络节点的总数。

(2) 小世界特征。平均路径长度和聚集系数是 衡量小世界特征的重要指标, 若网络呈现出较短路 径长度和较高聚集系数, 则网络的小世界特征显 著, 即网络的连通性和整体性较强, 通过改变少量 的连接节点, 就能显著地提高网络性能和效率。

平均路径长度是指网络中任意两点之间最短路 径的均值, 是衡量网络传输效率的全局属性指标。

$$
L=\frac{\sum_{i=j} d_{i j}}{n(n-1) / 2}
$$

式中: $L$ 为平均路径长度; $n$ 为网络中的节点数; $i, j$ 为 节点; $d_{i j}$ 表示 $i, j$ 之间的最短路径长度。

聚集系数表示网络节点的集聚程度, 即网络中 与某节点相邻的节点之间连接边的数量占最大可 能连边数量的比值。整体网络的聚集系数是指网 络中所有节点聚集系数的均值, 以反映网络节点的 局部特征。

$$
C=\frac{1}{n} \sum_{i=1} C_{i}
$$

式中: $C$ 为聚集系数; $n$ 为网络中节点总数。

(3) 凝聚子群。凝聚子群是在遵循相似性原则 下由彼此联系紧密、互动性强的节点构成的集合, 开展凝聚子群研究旨在揭示网络局部结构特征, 厘 清子群之间的相互关系。本文运用 UCINET 软件 中的 network/roles\&positions/structure/concer 方法 进行分析, 以识别网络的凝聚子群。

(4) 中心性与中心势。节点中心性表征节点在 空间网络中的功能和地位, 分为程度中心性、接近中 心性和中介中心性 3 个指标。程度中心性是衡量节 点在网络中的中心地位, 根据网络方向分为外向程 度中心性和内向程度中心性。介数中心性是衡量 网络节点作为 “中介者” 的能力, 即占据其他节点捷径 上的重要位置。接近中心性是衡量网络中某节点 到其他节点距离的远近程度, 即可达性。网络中心 势是指网络的整体中心性, 以反映网络的空间整合 度与网络发展的均衡程度, 包括程度中心势、介数 中心势及接近中心势。由UCINET 软件计算得出。

(5) 结构洞。用来判别网络中哪些节点具有优 势或劣势。节点拥有结构洞位置越多, 其竞争优 势、网络地位越重要; 同时, 由于缺乏可替代节点, 一定程度上阻碍了网络流动效率。通常利用效能 规模、效率性及约束性来衡量结构洞。由 UCINET 软件计算得出。

\section{4 镇村社区空间网络结构分析}

运用公式(1)计算出镇村社区之间的引力强度, 得出 $19 \times 19$ 的引力强度矩阵。将凤凰镇的 19 个镇 村社区抽象为网络节点, 镇村社区引力强度矩阵设 为连接边构建镇村社区空间网络。对赋值矩阵进 行二值化处理, 即两个节点引力强度值高于断点值 则为 1 , 反之为 0 ; 经过多次敏感性测试,选择“ 0.02 ” 为断点值, 将其转换为二值矩阵。基于此, 运用 UCINET 软件对二值矩阵进行对称化处理, 以 ArcGIS10.2 为平台实现网络结构图的可视化表达, 绘 制出镇村社区空间网络结构图(图 1)。

\section{1 镇村社区空间网络结构的总体特征}

\subsection{1 网络组织关系较为松散, 网络发育程度较低}

网络密度和网络中心势是衡量网络结构紧凑 性即网络空间紧密度与整合度的重要指标。运用 公式(4)计算出镇村社区空间网络密度为 0.481 , 在 最多可能出现 379 个网络联系数中, 出现了 183 个, 反映出网络空间紧密度较低、网络组织关系较为松 散。从图 2 中可以进一步看出引力强度具有向集镇 社区、社区 4 、社区18等节点集聚的态势,其他节点 的互动性较弱,联系较为稀疏。由 UCINET 软件计 算得出,镇村社区空间网络的外向和内向程度中心

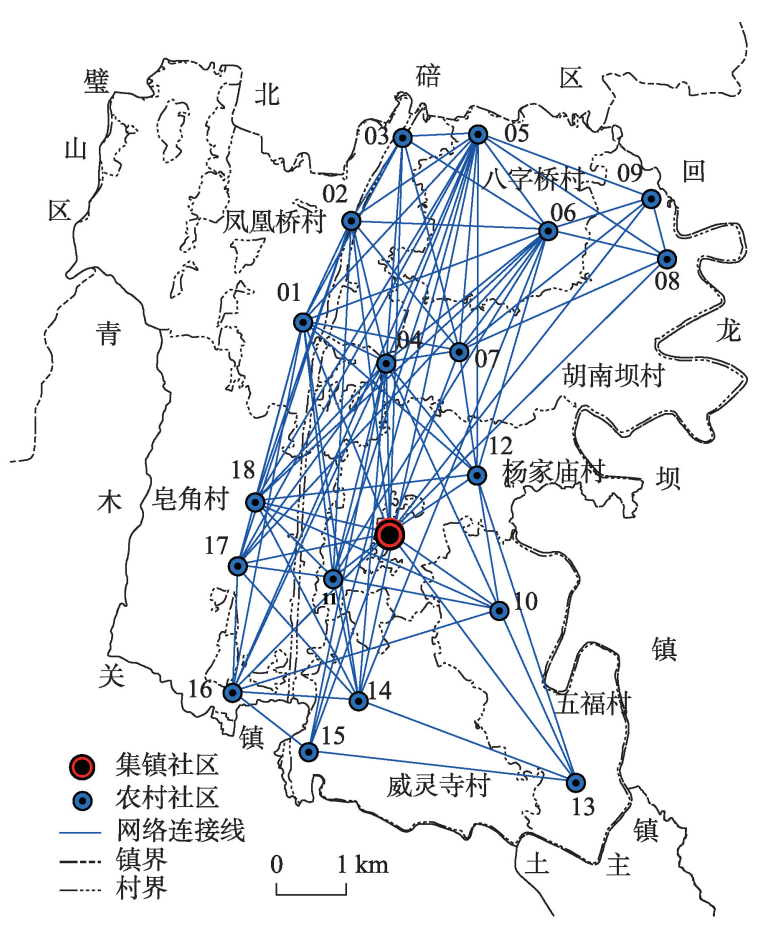

图 1 凤凰镇镇村社区空间网络结构图

Fig.1 Spatial network structure of village and town communities in Fenghuang Town, Chongqing Municipality 
势分别为 $42.48 \% 、 38.56 \%$, 外向和内向接近中心势 分别为 $53.95 \% 、 53.27 \%$, 介数中心势为 $10.06 \%$ 。相 较于 $100 \%$ 中心势值的星形网络, 中心势指标值均 较低, 表明镇村社区空间网络在较低水平、层次上 向中心集聚,网络总体的空间整合度较低、非均衡 性发展较为显著,整体网络受少数核心节点制约, 多数节点处于边缘地位, 网络具有核心-边缘结构 特征。总之, 整体网络处于低水平、非均衡的发展 阶段,网络发育程度较低。

4.1.2 网络连通能力较强, 小世界特征较为显著 根据公式(5)和(6) 可知, 网络平均路径长度为 1.363 , 说明网络中任意两点之间的平均距离位于 1 2之间, 大部分节点通过 1 2个中间社区建立联 系; 网络聚集系数为 0.774 , 表示网络节点集团化性 质明显、相邻节点联系较为紧密。镇村社区空间网 络具有较短的路径距离与较大的聚集系数, 呈现出 较为显著的小世界特征, 网络的整体性和连通性较 强。表明近年来的社区建设促使传统的亲缘邻里 乡村向业缘密切、群体规范、多元融合的现代社区 转变取得了较好的效果, 社区住户之间的文化认 同、信息交流逐渐增强, 对镇村社区之间的合作发 展具有推动作用。

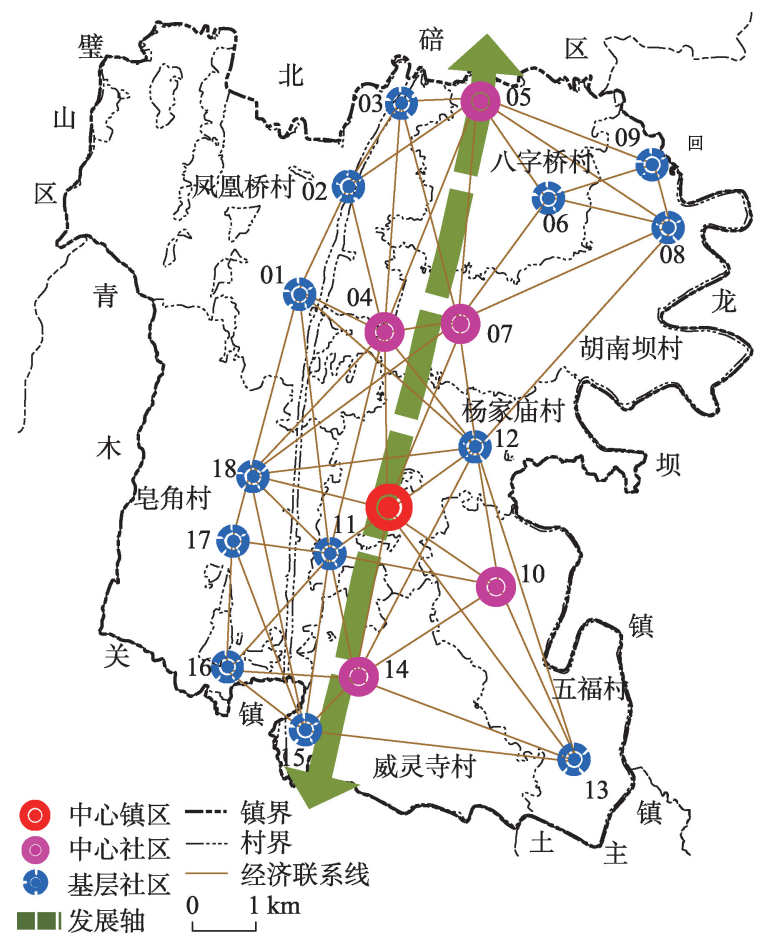

图 2 凤凰镇镇村社区空间网络化格局图

Fig.2 Spatial network pattern of the village and town communities in Fenghuang Town, Chongqing Municipality
4.1.3 网络局部集聚性较强,子群相互联系差异明显

运用 UCINET 的 Concer算法对镇村社区空间 网络进行凝聚子群分析,并根据节点之间联系的亲 疏程度识别网络内部的群体关系。由表 2 可知, 镇 村社区空间网络存在 6 个凝聚子群,表明网络内部 存在明显的“抱团”现象,局部集聚特征较强。

由表 3 可知,子群之间的相互联系强度差别较 大, 子群内部联系密切程度较低。从凝聚子群相互 联系来看, 以集镇社区、社区 11 构成的子群 1 与社 区 10 、社区 14 、社区 15 等构成的子群 5 联系最为紧 密, 以社区 13 构成的子群与其他子群之间的联系较 少; 从子群内部联系来看, 子群 $1>$ 子群 $5>$ 子群 $3>$ 子 群 2>子群 4>子群 6 ; 由于子群内部节点的区位条 件、相互作用等存在差异, 子群 1 对子群 5 、子群 3 的 辐射作用较为明显, 但对子群 4 、子群 6 联系较为薄 弱。可见,网络的局部集聚性特征显著, 各子群之 间的相互联系差异性明显。

\section{2 镇村社区空间网络结构的节点特征}

4.2.1 网络节点的中心性与层次性明显

由表 4 可知, 程度中心性指标的方差为 15.324 、 差距较大, 表明镇村社区网络结构呈现较强的不均 衡性; 集镇社区程度中心性高于其他节点, 属于镇 村社区信息流、物质流等的扩散门户,这与集镇社 区作为镇域行政中心密切相关。介数中心性指标

表 2 镇村社区空间网络凝聚子群

Tab.2 Cohesion subgroups of spatial network of village and town communities

\begin{tabular}{cl}
\hline 子群 & \multicolumn{1}{c}{ 成员 } \\
\hline 子群 1 & 集镇社区、社区 11 \\
子群 2 & 社区 1 、社区 2 、社区 3 、社区 5 \\
子群 3 & 社区 4 、社区 6 、社区 7 、社区 12 \\
子群 4 & 社区 8 、社区 9 \\
子群 5 & 社区 10 、社区 14 、社区 15 、社区 16、社区 17、社区 18 \\
子群 6 & 社区 13 \\
\hline
\end{tabular}

表 3 凝聚子群密度矩阵

Tab.3 Density matrix of subgroups

\begin{tabular}{ccccccc}
\hline 密度 & 1 & 2 & 3 & 4 & 5 & 6 \\
\hline 1 & 0.689 & 0.064 & 0.105 & 0.013 & 0.095 & 0.017 \\
2 & 0.064 & 0.246 & 0.120 & 0.081 & 0.196 & 0.005 \\
3 & 0.105 & 0.011 & 0.371 & 0.001 & 0.062 & 0.063 \\
4 & 0.013 & 0.033 & 0.081 & 0.127 & 0.044 & 0.002 \\
5 & 0.095 & 0.199 & 0.063 & 0.038 & 0.416 & 0.095 \\
6 & 0.017 & 0.002 & 0.005 & 0.008 & 0.105 & 0.052 \\
\hline
\end{tabular}

注: $R$-squared $=0.171$ 
表 4 镇村社区空间网络节点结构指标

Tab.4 Spatial network nodes structure index of village and town communities

\begin{tabular}{|c|c|c|c|c|c|c|c|c|}
\hline \multirow{2}{*}{ 社区节点 } & \multicolumn{2}{|c|}{ 程度中心性 } & \multirow{2}{*}{ 介数中心性 } & \multicolumn{2}{|c|}{ 接近中心性 } & \multicolumn{3}{|c|}{ 结构洞 } \\
\hline & 外向 & 内向 & & 外向 & 内向 & 效能规模 & 效率性 & 约束性 \\
\hline 集镇社区 & 18.000 & 18.000 & 35.692 & 99.000 & 99.000 & 7.940 & 0.441 & 0.206 \\
\hline 社区 1 & 11.000 & 11.000 & 2.962 & 69.231 & 72.000 & 2.714 & 0.247 & 0.331 \\
\hline 社区2 & 8.000 & 8.000 & 0.833 & 62.069 & 64.286 & 1.733 & 0.217 & 0.442 \\
\hline 社区3 & 6.000 & 6.000 & 0.521 & 60.000 & 60.000 & 1.667 & 0.278 & 0.551 \\
\hline 社区 4 & 15.000 & 15.000 & 8.425 & 85.714 & 85.714 & 4.333 & 0.289 & 0.247 \\
\hline 社区 5 & 17.000 & 17.000 & 21.959 & 94.737 & 94.737 & 6.647 & 0.391 & 0.219 \\
\hline 社区 6 & 11.000 & 8.000 & 4.450 & 69.231 & 72.000 & 3.000 & 0.273 & 0.330 \\
\hline 社区 7 & 15.000 & 15.000 & 14.597 & 85.714 & 85.714 & 5.267 & 0.351 & 0.247 \\
\hline 社区 8 & 5.000 & 5.000 & 0.000 & 58.065 & 58.065 & 1.000 & 0.200 & 0.648 \\
\hline 社区9 & 6.000 & 6.000 & 0.400 & 60.000 & 60.000 & 1.333 & 0.222 & 0.555 \\
\hline 社区 10 & 15.000 & 14.000 & 8.821 & 85.714 & 81.818 & 4.548 & 0.303 & 0.253 \\
\hline 社区 11 & 14.000 & 13.000 & 4.642 & 78.261 & 72.000 & 3.286 & 0.235 & 0.265 \\
\hline 社区 12 & 12.000 & 11.000 & 4.067 & 72.000 & 75.000 & 2.071 & 0.173 & 0.315 \\
\hline 社区 13 & 5.000 & 3.000 & 0.000 & 54.545 & 58.065 & 1.000 & 0.200 & 0.691 \\
\hline 社区 14 & 14.000 & 13.000 & 8.271 & 81.818 & 81.818 & 3.709 & 0.265 & 0.263 \\
\hline 社区 15 & 12.000 & 11.000 & 1.500 & 72.000 & 69.231 & 2.125 & 0.177 & 0.313 \\
\hline 社区 16 & 12.000 & 12.000 & 0.436 & 75.000 & 72.000 & 1.478 & 0.123 & 0.309 \\
\hline 社区 17 & 14.000 & 12.000 & 3.249 & 81.818 & 75.000 & 3.000 & 0.214 & 0.270 \\
\hline 社区 18 & 14.000 & 14.000 & 3.175 & 81.818 & 78.261 & 3.037 & 0.217 & 0.269 \\
\hline 均值 & 11.789 & 11.158 & 6.526 & 75.091 & 74.458 & & & \\
\hline 标准差 & 3.915 & 4.056 & 8.790 & 12.284 & 11.473 & & & \\
\hline 方差 & 15.324 & 16.449 & 77.262 & 150.897 & 131.630 & & & \\
\hline 最小值 & 5.000 & 3.000 & 0.000 & 54.545 & 58.065 & & & \\
\hline 最大值 & 18.000 & 18.000 & 35.692 & 99.000 & 99.000 & & & \\
\hline
\end{tabular}

显示平均每个节点充当网络中介者的次数为 6.526 , 但中介性方差达 77.262 , 仅有 6 个节点的介 数中心性大于均值, 起到了中介作用, 占据了资源 和信息流通的关键位置, 具有较高进人性, 其他节 点对这 6 个节点具有较强的依赖性。接近中心性指 标显示, 外向与内向接近中心性均值分别为 75.091 和 74.458, 节点间联系相对紧密。同时, 各节点可 达性差异较大,如集镇社区的接近中心性值最高, 反映出集镇社区可达性好, 与其他节点均联系密 切, 在网络中处于核心地位; 而社区 13 、社区 8 及社 区9 的接近中心性指数最低, 在空间网络结构中基 本被孤立。

集镇社区的各项中心性指标均为最高值, 反映 出集镇社区是镇村社区空间网络中心, 是整个网络 的核心。社区 5 、社区 7、社区 4、社区 10 和社区 14 的集聚和辐射能力较强, 属于次级核心, 从指标值 可以看出这 5 个节点间的互动较多, 主要得益于相
互距离较近、交通网络较为完善。由于社区 5 、社区 7、社区 4 、社区 10 和社区 14 的引力强度较大, 应充 分发挥其对周边的辐射作用以及与集镇社区的承 接功能。其余社区的网络地位、可达性相对较弱, 相互联系较为稀疏。因此,网络节点结构是以集镇 社区为核心、社区 5 、社区 7、社区 4、社区 10 和社区 14 为次核心并与其他社区构成的 3 级节点体系。

\subsection{2 核心节点的结构洞优势有待加强}

采用UCINET 软件对镇村社区空间网络进行 结构洞分析(表 4), 可知集镇社区的效能规模与效率 性最大、约束性最小, 在镇村社区空间网络中结构 洞水平高且占据主导优势; 社区 5、社区 7、社区 4、 社区 10 及社区 14 等核心节点在网络中占据较多的 结构洞优势和竞争机会, 对网络的辐射引导作用较 大, 同时由于缺乏替代性节点,一定程度上会导致 要素流动的瓶颈出现。因此,需要进一步加强软硬 件建设、完善服务体系, 合理引导要素流动; 社区 
13、社区 8 及社区 9 的效能规模、效率性最小, 在网 络竞争中处于劣势地位, 应加大资源禀赋开发、服 务设施建设的力度, 强化与社区 5 、社区 7、社区 4、 社区 10 及社区 14 等具有结构洞优势节点的交流、 互动。

\section{3 镇村社区空间网络结构的差异特征}

镇村社区相互联系主要是通过社区居民之间 的交往、互动体现, 社区居民的社会属性、交往行为 不同,对镇村社区空间网络结构将产生不同影响。 因此, 本文以网络密度、介数中心势、小世界值为待 检测变量, 运用SPSS 22.0 的 Pearson相关性分析检 测家庭收人、受教育程度、邻里关系、主要生计来 源、人住年份及居住满意度等社会属性与检测变量 之间的关联性。结果显示: 人住年份、受教育程度、 邻里关系、家庭收人、主要生计来源、居住满意度与 网络结构具有显著相关性。

由表 5 可知, 居民人住年份、邻里关系、主要生 计来源及居住满意度与空间紧密度、空间整合度呈 现显著的正相关性, 且居住满意度的相关性 $(P \leqslant$ 0.05 )较为可靠, 即居民人住时间越长、居住满意度 越高, 与邻里关系越密切、生计来源呈现兼业化, 则 与其他社区的交往活动、分工合作越频繁, 使得空 间网络的连通性、紧密度及整合度越高。居民家庭 收人与空间紧密度、整合度呈现显著且可靠的负相 关性, 且居民受教育程度与空间紧密度、空间连通 性呈现显著而又可靠的负相关性。表明居民的受 教育程度越高、经济条件越好, 他们的交往活动和

表 5 镇村社区空间网络结构与居民特征相关性分析

Tab.5 Correlation analysis of spatial network structure and resident characteristics of village and town communities

\begin{tabular}{llccc}
\hline 居民属性 & \multicolumn{1}{c}{ 项目 } & $\begin{array}{c}\text { 空间紧密 } \\
\text { 度(密度) }\end{array}$ & $\begin{array}{c}\text { 空间整合度 } \\
\text { (介数中心势) }\end{array}$ & $\begin{array}{c}\text { 空间连通性 } \\
\text { (小世界值) }\end{array}$ \\
\hline 人住年份 & 相关系数 & 0.660 & 0.760 & 0.640 \\
& $\mathrm{P}$ 值 & 0.570 & 0.440 & 0.370 \\
受教育程度 & 相关系数 & -0.670 & 0.560 & -0.110 \\
& $\mathrm{P}$ 值 & 0.040 & 0.550 & 0.030 \\
邻里关系 & 相关系数 & 0.300 & 0.410 & 0.380 \\
& $\mathrm{P}$ 值 & 0.550 & 0.860 & 0.450 \\
家庭收人 & 相关系数 & -0.690 & -0.450 & -0.800 \\
& $\mathrm{P}$ 值 & 0.030 & 0.010 & 0.410 \\
主要生计来源 & 相关系数 & 0.210 & 0.500 & 0.260 \\
& $\mathrm{P}$ 值 & 0.250 & 0.840 & 0.630 \\
居住满意度 & 相关系数 & 0.740 & 0.610 & 0.330 \\
& $\mathrm{P}$ 值 & 0.050 & 0.030 & 0.010 \\
\hline
\end{tabular}

通勤距离越远, 受到城市影响越强, 就越有机会享 受城市核心区的优质服务。在镇村社区配套设施 不完善时,促使其交往行为与休闲活动具有明显的 外部性,而发生在镇村社区之间的活动频率降低, 从而降低了镇村社区空间网络的紧密度、整合度。

\section{5 镇村社区空间网络结构的优化策略}

凤凰镇镇村社区空间网络整体处于低水平、非 均衡的发展阶段,网络总体松散性与局部集聚性并 存,网络空间紧密度、整合度较低,凝聚子群的相互 联系较弱,核心节点的辐射作用、结构洞优势有待 提升。基于此, 从节点自身功能完善、节点等级体 系构建、节点间经济联系强化等方面人手, 结合区 域实际状况与村域产业特色,制定“1 轴、 1 心、18 点”+“1 网、57线”的空间网络化模式, 以提升网络 发展水平,促进空间组织网络化。

(1) 优化社区空间, 完善节点自身功能。社区 居民的社会属性、多元诉求的差异,促使其对于网 络结构产生不同影响。应加强镇村社区的软硬件 设施建设,特别是文化设施与公共空间建设, 丰富 社区居民的交流形式, 提升社区居民的满意度、归 属感; 增强社区之间的功能互补性与服务范围, 满 足社区住户与周围农户的多重需求, 吸引农户人 住, 强化社区住户之间的业缘地缘关系, 以提升社 区人口流动效率。

(2) 明确社区定位,构建节点等级体系。结合 镇村社区空间网络的节点中心性与等级结构特征, 进一步完善核心节点, 加快边缘节点发展, 构建“中 心镇区-中心社区-基层社区”3 级网络节点体系。 首先, 集镇社区作为网络核心, 将其定义为中心镇 区,并进一步完善公共服务体系,使其成为集政治、 经济、文化、科教等于一体的综合服务中心; 其次, 将社区 5、社区 7、社区 4、社区 10 和社区 14 等次核 心定义为中心社区, 作为连接镇村的联结点与村域 政治、经济、文化中心, 完善日常生活服务设施, 为 自身和其他农村居民点提供公共服务和支农服务; 再次,边缘节点定义为基层社区,作为村域内农业 生产生活组织的聚居地, 对周围农村居民点起到带 动作用。最后, 形成等级有序、互联互通的网络节 点体系, 促进节点功能的有效发挥。

(3) 拓宽联系通道, 强化节点间经济联系。镇 村社区空间网络总体上呈现的低水平、不均衡的发 
育状态, 导致社区发展动力不足、相互联系不畅。 因此, 必须强化社区经济关联以增强驱动力, 完善 通道媒介以保障沟通顺畅。一方面, 根据镇村社区 之间的交通、通讯等基础条件,完善包括交通线路、 信息通道及生态通道等联系通道,增强核心节点与 边缘节点之间的交流、互动; 另一方面, 基于区域产 业基础与经济条件, 以社区为联络点,进一步挖掘 村域产业资源,促进产业发展与社区建设的协调推 进, 提升社区的产业支撑力与社区居民的财产性收 人, 扩大社区居民就业率, 增强社区间经济联系, 促 进区域要素合理流动与经济互补发展, 实现农村社 区建设与农业产业化的双驱联动。

(4) 厘清网络要素作用, 制定空间网络化模 式。通过节点自身功能完善促进了社区间人口流 动, 构建节点等级体系增强了社区的纵横联系, 强 化节点经济联系培育了网络驱动力; 结合镇村的发 展环境与基础条件,制定出“1轴、1 心、18 点”+“1 网、57线”的空间网络化模式。由图 2 可知, “1 轴” 即将贯穿镇域、连接中心镇区、中心社区和基层社 区的南北向通道定义为区域发展轴,构成区域镇村 社区空间网络发展的主要方向; “1心”即凤凰镇集 镇社区, 是镇域综合发展中心和中心镇区, 是镇域 发展的辐射源和驱动力; “ 18 点”即由 5 个中心社区 和 13 个基层社区构成, 是镇村社区网络结构的关键 节点和镇域发展的辅助推动力; “ 1 网” 即由 1 心 18 点为网络控制点, 综合各控制点的区位、功能、产业 等方面交织互辅形成的“镇村网络”结构; “57线”即 57 条镇村社区网络经济联络线,形成以人口流动、 经济流通、产业互补、区位特色、交通便利、文化相 融为依托的镇村网络联络线, 也是形成网络结构的 “经济流”。最终实现镇村社区之间人口、经济、产 业、技术等在网络中的高效配置与自由流动。

\section{6 结论与讨论}

凤凰镇镇村社区空间网络兼具整体松散性与 局部集聚性的双重特征,整体网络处于低水平、非 均衡的发展阶段。网络组织关系较为松散, 网络发 育不均衡, 核心-边缘结构特征较为明显; 网络内社 区之间的平均距离介于 $1 \sim 2$ 之间,且聚类系数较高, 网络的小世界特征较为显著, 网络的整体性与连通 性较强; 网络具有 6 个凝聚子群, 网络的局部集聚特 征明显,且各子群之间的联系存在差异性。
网络节点的中心性与等级结构特征较为显著, 形成了以集镇社区为核心,社区 5、社区7、社区 4、社 区 10 和社区 14 为次核心及其他社区的 3 级节点体 系。虽然核心节点在网络流通中扮演着结构洞角 色、竞争优势较为明显,但由于缺乏替代性节点, 可能 会导致要素流动的瓶颈出现。因此,需进一步完善 核心节点的服务设施, 合理引导要素流动, 加大节 点之间的互动合作, 以提升整体网络性能与效率。

社区居民不同的社会属性对镇村社区空间网 络结构造成了差异影响。根据分析结果可知, 社区 居民人住年份、邻里关系、生计来源及居住满意度与 空间紧密度、整合度有显著的正相关性,但只有居住 满意度的相关性较为可靠; 居民家庭收人与空间紧 密度、整合度, 居民受教育程度与空间紧密度、连通 性均呈现出显著且可靠的负相关性。说明居民的 业缘地缘关系对网络结构的作用日益重要, 同时, 需要完善社区服务功能, 以满足居民的多元诉求。

基于网络结构特征, 从节点自身功能完善、节 点等级体系构建及节点间经济联系强化等方面着 手,结合区域实际状况与村域产业特色,构建了“1 轴、1心、18点”+ “1 网、57线”的镇村社区空间网络 化模式, 为城乡一体化推进中镇村社区资源的合理 配置提供了新的思路与方法。

厘清镇村社区间的网络联系, 并制定社区空间 网络化模式,成为提升网络运行效率、区域协调发 展的着力点。本文在构建镇村社区空间网络基础 上定量分析空间网络结构, 揭示其总体、节点及差 异特征。基于此, 提出社区空间网络化的优化策 略, 为理清镇村社区网络发展状况并优化其网络结 构提供一新思路。与覃永晖等(2016)基于网络形镇 村体系等级结构的实证研究相比, 突破了以传统的 镇村体系研究镇村空间结构的范式, 以镇村体系重 要组分即镇村社区为切人点研究其空间网络结构, 有利于进一步探究与准确把握镇村空间组织的特 征、规律, 为镇村协同发展、城乡融合发展提供新方 法与新视角。随着社会经济发展,镇村社区空间网 络处于不断发展状态, 因而对其演变过程及驱动因 素的探究将成为今后研究的重点。

\section{参考文献(References)}

蔡进, 邱道持, 赵梓琰, 等. 2013. 新型农村社区人居环境变 化研究: 以重庆市忠县天子村社区为例 $[J]$. 西南大学学 报: 自然科学版, 35(10): 117-124. [Cai J, Qiu D C, Zhao Z $\mathrm{Y}$, et al. 2013. A research of the changes in residential envi- 
ronment in new rural communities: A case study of Tianzi Village of Zhongxian County[J]. Journal of Southwest University: Natural Science, 35(10): 117-124.]

蔡进, 禹洋春, 朱莉芬, 等. 2015. 新型农村社区建设对农户 生计变化影响研究: 以三峡库区重庆市忠县天子村社区 为例 $[J]$. 地域研究与开发, 34(4): 143-147, 157. [Cai J, Yu Y C, Zhu L F, et al. 2015. Research on farmers' livelihoods changes under the new rural community construction taking Tianzi Village of Zhongxian County, Chongqing City as an example[J]. Areal Research and Development, 34(4): 143-147, 157.]

杜相佐, 王成, 蒋文虹, 等. 2015. 基于引力模型的村域农村 居民点空间重构研究: 以整村推进示范村重庆市合川区 大柱村为例 [J]. 经济地理, 35(12): 154-160. [Du X Z, Wang C, Jiang W H, et al. 2015. Rural settlements restructuring based on analysis of the gravity model at village level: The case of Dazhu Village, Chongqing, China[J]. Economic Geography, 35(12): 154-160.]

付琼鸽, 刘大均, 胡静, 等. 2015. 湖北省旅游流网络结构的 特征与优化 [J]. 经济地理, 35(3): 191-196. [Fu Q G, Liu D J, Hu J, et al. 2015. Network structure and optimization research on the Hubei Province tourist flow $[\mathrm{J}]$. Economic Geography, 35(3): 191-196.]

侯贺平, 刘艳芳, 李纪伟, 等. 2013. 基于改进辐射模型的乡 镇人口流动网络研究 $[\mathrm{J}]$. 中国人口・资源与环境, 23(8): 107-115. [Hou H P, Liu Y F, Li J W, et al. 2013. Study on population mobility network among towns based on improved radiation model[J]. China Population, Resources and Environment, 23(8): 107-115.]

惠怡安, 和钟, 马恩朴, 等. 2014. 基于社会网络的黄土丘陵 沟壑区镇村体系认识: 以延安市延长县安沟乡为例 [J]. 人文地理, 29(1): 108-112. [Hui Y A, He Z, Ma E P, et al. 2014. Study on the town-and-village system based on interpersonal contact in loess hilly-gully region: A case study in Angou Town, Yan Chang County, Yan'an[J]. Human Geography, 29(1): 108-112.]

蒋文虹, 王成, 刘怡, 等. 2015. 基于物元可拓模型的新型农 村社区管护绩效评价: 以重庆市整村推进示范村 “大柱 新村”为例 [J]. 西南大学学报: 自然科学版, 37(2): 110116. [Jiang W H, Wang C, Liu Y, et al. 2015. Evaluation of the managing and maintaining performance of new rural communities based on matter element extension mode: A case study of Dazhu New Village, the entire- village advancement demonstration village in Chongqing $[\mathrm{J}]$. Journal of Southwest University: Natural Science Edition, 37(2): 110-116.]

李亚婷, 潘少奇, 苗长虹. 2014. 中原经济区县际经济联系网 络结构及其演化特征 [J]. 地理研究, 33(7): 1239-1250.
[Li Y T, Pan S Q, Miao C H. 2014. Structure and evolution of economic linkage network at county level in Central Plains Economic Zone[J]. Geographical Research, 33(7): 1239-1250.]

刘军. 2004. 社会网络分析导论[M]. 北京: 社会科学文献出 版社. [Liu J. 2004. An introduction to social network analysis[M]. Beijing, China: Social Sciences Academic Press.] 刘耀林, 范建涁, 李楚琪, 等. 2016. 基于改进引力模型的镇 域村镇等级体系定量化研究 [J]. 农业现代化研究, 37(1): 158-165. [Liu Y L, Fan J B, Li C Q, et al. 2016. Townbased quantitative analysis of the town-and-village hierarchy system using an improved gravity model[J]. Research of Agricultural Modernization, 37(1): 158-165.]

乔家君. 2012. 乡村社区空间界面理论研究 [J]. 经济地理, 32 (5): 107-112. [Qiao J J. 2012. Study on the spatial interface theory of rural community $[\mathrm{J}]$. Economic Geography, 32(5): 107-112.]

石忆邵, 杭太元. 2013. 我国城乡一体化研究的近期进展与 展望 [J]. 同济大学学报: 社会科学版, 24(6): 50-57. [Shi Y S, Hang T Y. 2013. Recent progress in and prospects of urban-rural integration research in China[J]. Tongji University Journal of Social Science Section, 24(6): 50-57.]

覃永晖, 彭保发, 王晶. 2014. 镇村体系网络化规划研究: 以 常德市桃源县木塘垸乡为例 [J]. 经济地理, 34(9): 56-62. [Qin Y H, Peng B F, Wang J. 2014. The networked townand- village system: A case study on Mutangyuan Town, Taoyuan County, Changde City[J]. Economic Geography, 34(9): 56-62.]

覃永晖, 彭保发, 王晶. 2016. 网络形镇村体系等级结构的实 证研究 [J]. 经济地理, 36(7): 84-90. [Qin Y H, Peng B F, Wang J. 2016. The research of network-shaped hierarchical structure of town and village system[J]. Economic Geography, 36(7): 84-90.]

王凤, 刘艳芳, 孔雪松, 等. 2016. 基于社会网络理论的农村 社会空间联系分析: 以武汉市黄陂区李集镇为例 [J]. 经 济地理, 36(4): 141-148, 202. [Wang F, Liu Y F, Kong X S, et al. 2016. Analysis of spatial interaction in rural society based on theory of social network: A case of Liji Town in Wuhan City[J]. Economic Geography, 36(4): 141- 148, 202.]

危小建, 肖展春, 侯贺平, 等. 2017. 基于复杂网络的辽宁省 县域农村居民点空间结构变化分析 [J]. 农业工程学报, 33(8): 236-244. [Wei X J, Xiao Z C, Hou H P, et al. 2017. Analysis of spatial structure changes of rural residential area in counties of Liaoning Province based on complex network[J]. Transactions of the Chinese Society of Agricultural Engineering, 33(8): 236-244.]

叶琴丽, 王成. 2015. 基于结构方程模型的集聚农户共生认 
知及影响因素分析: 以重庆市为例 [J]. 中国土地科学, 29 (4): 82-89. [Ye Q L, Wang C. 2015. Cognition and its impact factors on the scale effects of village agglomeration based on the structural equation model: Taking Chongqing as example[J]. China Land Sciences, 29(4): 82-89.]

喻新安, 刘道兴. 2013. 新型农村社区建设探析[M]. 北京: 社 会科学文献出版社. [Yu X A, Liu D X. 2013. Study on the construction of the new rural community[M]. Beijing, China: Social Sciences Academic Press.]

苑露莎. 2014. 基于复杂网络的农村居民点空间布局优化研 究[D]. 北京: 中国地质大学(北京). [Yuan L S. 2014. Research on spatial distribution optimization of rural settlement based on complex network[D]. Beijing, China: China University of Geosciences, Beijing.]
甄茂成, 张景秋, 杨广林. 2013. 基于复杂网络的商业银行网 点布局特征: 以北京市中国银行为例 $[\mathrm{J}]$. 地理科学进展, 32(12): 1732-1741. [Zhen M C, Zhang J Q, Yang G L. 2013. Characteristics of commercial bank branch networks based on complex networks theory: A case study on Bank of China in Beijing $[\mathrm{J}]$. Progress in Geography, 32(12): 1732-1741.]

邹晴晴, 王勇, 李广斌. 2016. 基于 SNA 的新型集中社区公共 空间网络结构优化 [J]. 地理科学进展, 35(7): 829-838. [Zou Q Q, Wang Y, Li G B. 2016. Network structure optimization of public space in new concentrated communities based on SNA[J]. Progress in Geography, 35(7): 829-838.]

Thomas H D J. 1982. Urbangeoere Phy: Afirstap Proaeh[M]. New York: Jhon Willey \& Sons.

\title{
Structural characteristics and optimization strategies of the spatial network of village and town communities
}

\author{
SU Rui ${ }^{1,2}$, WANG Cheng ${ }^{1,2^{*}}$, TANG Ning ${ }^{1,2}$, PENG Qing ${ }^{1,2}$, LONG Yuqin ${ }^{1,2}$ \\ (1. School of Geographical Sciences, Southwest University, Chongqing 400715, China; \\ 2. Chongqing Key Laboratory of Karst Environment, Chongqing 400715, China)
}

\begin{abstract}
Spatial network of village and town communities is a spatial organization form that relies on the town and takes the village and town communities as nodes and connections between nodes as edges. Exploring its structural characteristics and optimization strategies is of great significance for guiding the sound flow of factors and improving network operation efficiency. By selecting 19 village and town communities in Fenghuang Town of Shapingba District, Chongqing Municipality as network nodes, this study applied the modified gravitational intensity model to explore the connections between these nodes. Using GIS tools, social network analysis method, and correlation analysis method, this study examined the general characteristics, node characteristics, and characteristics of difference of the spatial network structure of the village and town communities, and established the network optimization strategies. The results show that the spatial network of the village and town communities is in a low level, unbalanced stage of development, which possess characters of both general looseness and local agglomeration, the small world characteristic, and the association difference between cohesive subgroups is significant. The spatial network of the village and town communities exhibited a 3-level node structure that takes the town community as the core, community $5,7,4,10$, and 14 as secondary cores, and contains the other communities, among which the structural hole advantage of the core nodes needs further enhancing. Various social attributes of community residents cause different effects to the network structure. On these bases, this study constructed a "one axis, one core, eighteen nodes, one network, and fifty-seven links" spatial network pattern by improving functions of the nodes, building the node hierarchy, and strengthening economic relations among nodes, and therefore providing a demonstration for current and future rural community construction.
\end{abstract}

Key words: village and town communities; spatial network structure; optimization strategies; Fenghuang Town; Chongqing Municipality 